A) Check for updates

Cite this: Food Funct., 2018, 9, 6205

\section{Enhancing the antimicrobial and antifungal activities of a coloring extract agent rich in betacyanins obtained from Gomphrena globosa L. flowers $\uparrow$}

\author{
Custódio Lobo Roriz, (D) ${ }^{\text {a,b }}$ Lillian Barros, (DD*a M. A. Prieto, (DD ${ }^{\text {a,c }}$ Ana Ćirić, ${ }^{d}$ \\ Marina Soković, (D) ${ }^{d}$ Patricia Morales (DD ${ }^{\text {b,e }}$ and Isabel C. F. R. Ferreira (D) $*^{a}$
}

Received 17th September 2018, Accepted 31st October 2018

DOI: $10.1039 / c 8 f 001829 d$

rsc.li/food-function

\begin{abstract}
Although less explored than beetroot (Beta vulgaris L.), the flowers of Gomphrena globosa L. are a very suitable source of betacyanins with strong pigmentation features, together with many other desirable bioactive properties. Thus, the aim of this study was to enhance the antimicrobial and antifungal activities of a pigmented extract obtained from G. globosa flowers by ultrasound assisted extraction (UAE). The procedure was supported with the application of the response surface methodology, a robust optimization technique that allows to study jointly the effects of several variables and responses. To enhance the antimicrobial (Bacillus cereus, Listeria monocytogenes, Escherichia coli and Salmonella typhimurium) and antifungal (Aspergillus flavus, Aspergillus niger, Penicillium ochrochloron and Penicillium verrucosum) activities, the responses were evaluated in terms of the concentrations needed to obtain minimum inhibitory (MIC), minimum bactericidal (MBC) and minimum fungicidal (MFC) concentrations. It was found that the optimal UAE conditions were $10.8 \mathrm{~min}, 410.5 \mathrm{~W}, 57.8 \%$ of ethanol, and $5 \mathrm{~g} \mathrm{~L}^{-1}$ of the solid-liquid ratio providing the following response values: (1) from the studied species of bacteria, the MIC ranged from $\sim 0.15$ to $0.35 \mathrm{~g} \mathrm{~L}^{-1}$ and the $\mathrm{MBC}$ ranges were $\sim 0.30$ to $0.65 \mathrm{~g} \mathrm{~L}^{-1}$; and (2) from the studied fungus species, the MIC ranged from $\sim 0.20$ to $0.30 \mathrm{~g} \mathrm{~L}^{-1}$ and the MFC ranges were $\sim 0.40$ to $0.65 \mathrm{~g} \mathrm{~L}^{-1}$. The antibacterial activity dose levels were lower than the antifungal ones. In conclusion, the results obtained in this study highlight extracts from G. globosa flowers as natural sources of betacyanins with application as food colorants with important antimicrobial and antifungal activities.
\end{abstract}

\section{Introduction}

Infectious diseases caused by bacteria and fungus are the cause of serious illness and death of a high number of people every year. ${ }^{1}$ Although the world statistical information shows over 50000 deaths every year, the numbers could be higher

\footnotetext{
${ }^{a}$ Centro de Investigação de Montanha (CIMO), Instituto Politécnico de Bragança, Campus de Santa Apolónia, 5300-253 Bragança, Portugal. E-mail: iferreira@ipb.pt, lillian@ipb.pt; Fax: +351-273-325405; Tel: +351-273-303219, +351-273-303285

${ }^{b}$ Dpto. Nutrición y Ciencia de los Alimentos. Facultad de Farmacia. Universidad Complutense de Madrid (UCM), Plaza Ramón y Cajal, s/n, E-28040 Madrid, Spain ${ }^{c}$ Nutrition and Bromatology Group, Faculty of Food Science and Technology, University of Vigo, Ourense Campus, E32004 Ourense, Spain

${ }^{d}$ Institute for Biological Research "Siniša Stankovic", Department of Plant Physiology, University of Belgrade, Bulevar Despota Stefana 142, 11000 Belgrade, Serbia ${ }^{e}$ ALIMNOVA Research Group. Facultad de Farmacia. Universidad Complutense de Madrid (UCM), Plaza Ramón y Cajal, s/n, E-28040 Madrid, Spain

$\dagger$ Electronic supplementary information (ESI) available. See DOI: 10.1039/ c8fo01829d
}

due to the reduced number of reports available in developing countries. $^{2,3}$ The antimicrobial qualities of plants and their extracts have been recognized since antiquity, while attempts to characterize these properties in the laboratory date back to the early 1900s. ${ }^{4}$ The new advances have aided a more quick characterization and confirmed the potential efficacy of plantbased extracts against various bacterial and fungal pathogens. ${ }^{5,6}$ Although most of the compounds found in plantbased extracts are not of much help in fighting the microbial diseases directly, they could be helpful at the industrial level as food additives to prevent spoilage, contamination and dissemination of microbial diseases (foodborne diseases). Industrial preservation and decontamination processes are applied to prevent the growth of microorganisms in food and facilitate its storage and transportation. ${ }^{7-9}$ Therefore, some of the attention of the research community in food science has shifted to screen out natural food additives with a potential composition that could enhance antimicrobial protection in food products. 
Nowadays, it is well known that a diverse diet based on a daily intake of fruits and vegetables is able to diminish the risk of developing chronic diseases. ${ }^{10}$ This is due to the rich variety of bioactive compounds (such as vitamins, minerals, phenolics, among others) present in these foods, which are known to help maintain the redox homeostasis and play an important role in health promotion and disease prevention. ${ }^{11}$

Among these compounds are the natural pigments, which in addition to their coloring attributes display strong bioactive properties, especially antimicrobial capacity. Most well-known plant natural pigments consist of carotenoids, chlorophylls, anthocyanins, and betalains. Although the first two types are deposited in particular plastids in plant cells, the last two are located in the vacuoles. ${ }^{12}$ Betalains are water-soluble vacuolar chromoalkaloids, that are subdivided according to their chemical structure into red-violet betacyanins and yellow betaxanthins. ${ }^{13}$

Betacyanins have been described as possessing many desirable properties, such as hypoglycaemic and hypolipidemic action, antimicrobial activity (antibacterial and antifungal), ${ }^{14,15}$ and the ability to inhibit cell growth and induce ultra-structural changes and cell fragmentation on carcinogenic cells. ${ }^{16,17}$ These red-purple pigments constitute an optimal example of natural additives used as food colorants, displaying noticeable coloring attributes, as well as various in vitro and in vivo biological properties. ${ }^{18}$

The most common source of betacyanins is beetroot (Beta vulgaris L.); nonetheless, the flowers of Gomphrena globosa L. are a suitable alternative source of these compounds despite being less explored. ${ }^{19}$ This plant has been associated with several health promoting properties, being used in the treatment of several diseases, such as respiratory system diseases, diabetes, jaundice, hypertension, urinary system conditions, and kidney and prostate problems. ${ }^{20}$ Nonetheless, due to its intense coloration of G. globosa flowers, it is also an excellent candidate for the recovery of compounds with coloring capacity. A recent study demonstrated that the ultrasound assisted extraction (UAE) technique was one of the most successful and efficient ways to produce a rich colorant extract for industrial applications. ${ }^{21}$ In consequence, the potential natural additive derived from the flowers of G. globosa could be optimized in order to enhance the antimicrobial activity.

When developing natural additives, the costs of the processes is as relevant as many other factors, and could be a handicap that limits it applications due to the low production costs of artificial additives. ${ }^{22,23}$ In consequence, to make the extraction process as economically viable as possible, optimizing the operational conditions is a crucial basic research step. Variables like time, energy and solvent proportion need to be jointly optimized in order to obtain productive results at an industrial level. Additionally, it is important to emphasize that the betacyanin concentrations used to achieve functional benefits are significantly different (normally higher) from those used for colorant purposes ${ }^{24}$ and therefore, the variable solid-to-liquid ratio becomes an essential part of the analytical work to be performed. In this regard the statistical approach of the response surface methodology (RSM) is a commonly used tool, improving and optimizing processes with multiple variables and/or factors. ${ }^{25}$

In conclusion, the aim of this study was to evaluate the possibility of obtaining extracts rich in betacyanins with enhanced antimicrobial activity using the flowers of G. globosa. In order to achieve this goal, the extracts were obtained by ultrasound assisted extraction (UAE) in order to maximize the antimicrobial activity, with the support of RSM.

\section{Materials and methods}

\subsection{Sample collection}

Gomphrena globosa L. was purchased from Ervital (Portugal), settled in a high diverse mountain region. The harvested plants were processed using in-storage and low temperature drying methods as previously described by the authors. $^{21}$

\subsection{Ultrasound assisted extraction}

The UAE was carried out using an ultrasonic device (QSonica sonicators, model CL-334, Newtown, CT, USA), equipped with a digital timer, and working in the range of 100 to $500 \mathrm{~W}$, at a frequency of $20 \mathrm{kHz}$. The used solvent volume was settled at $50 \mathrm{~mL}$. The samples were extracted according to different conditions regarding: time $(t$, in $\min )$, power $(P$, in $\mathrm{W})$, water-ethanol proportion $(S$, in \%) and solid-to-liquid ratio $\left(\mathrm{S} / \mathrm{L}\right.$, in $\left.\mathrm{g} \mathrm{L}^{-1}\right)$, as defined by the RSM design (Table A1, at the ESI $\dagger$ ), and as previously published. ${ }^{26}$ These extracts have also been formerly characterized and quantified in terms of their

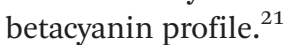

\subsection{Evaluation of antimicrobial properties}

2.3.1 Antibacterial activity. The antibacterial activity was assayed using a procedure previously described. ${ }^{27}$ Two categories of bacteria were used: (1) Gram-positive bacteria, Bacillus cereus (clinical isolate, coded in this study as $\mathrm{B}_{1}$ ) and Listeria monocytogenes (NCTC7973, $\mathrm{B}_{2}$ ), and (2) Gram-negative bacteria, Escherichia coli (ATCC 35210, $\mathrm{B}_{3}$ ) and Salmonella typhimurium (ATCC 13311, $\mathrm{B}_{4}$ ).

2.3.2 Antifungal activity. The antifungal activity was assayed using the procedure previously described. ${ }^{28}$ The following microfungi were used: Aspergillus flavus (ATCC1022, $\mathrm{F}_{1}$ ), Aspergillus niger (ATCC6275, $\mathrm{F}_{2}$ ), Penicillium ochrochloron (ATCC9112, $\mathrm{F}_{3}$ ) and Penicillium verrucosum var. cyclopium (food isolate, $\mathrm{F}_{4}$ ).

2.3.3 Microbial inhibition analysis. Bacterial and fungal organisms were obtained from the Mycological Laboratory, Department of Plant Physiology, Institute for Biological Research "Sinisa Stanković, University of Belgrade, Serbia. 
The minimum inhibitory concentration (MIC), minimum bactericidal concentration (MBC) and minimum fungicidal concentration (MFC) were determined by methodologies previously described. ${ }^{29}$ Streptomycin was used as the positive control for bacteria growth, while ketoconazole was used as the control for fungi growth. All the response variables were uniformed in grams of the extracted material per liter of the solution applied in the microbial tests $\left(\mathrm{g} \mathrm{L}^{-1}\right)$. In all cases the assays were carried out in triplicate. The results were expressed as mean values and standard deviation (SD).

\subsection{Experimental design, model analysis and statistical evaluation}

2.4.1 Experimental design. The influence of different independent variables was investigated using one-factor-at-a-time to select the significant ones and determine the preliminary range of the processing variables. Based on these experimental results (data not shown), the selected significant variables for the RMS design were: $X_{1}$ (time in min), $X_{2}$ (power in W), $X_{3}$ (ethanol content in \%) and $X_{4}$ (solid/liquid ratio in $\mathrm{g} \mathrm{L}^{-1}$ ). Therefore, the combined effect of these four variables on the antimicrobial activity was studied using circumscribed central composite design (CCCD) as proposed by Box. ${ }^{30}$ The responses were solved using 28 independent combinations and four replicates as the center of the experimental design. In this design, the points of experiments are generated on a sphere around the center point. The center point is supposed to be an optimum position for the response and is repeated to maximize the prediction. ${ }^{21}$ This design also requires five levels for each factor. Experimental runs were randomized to minimize the effects of unexpected variability in the observed responses. A detailed description of the mathematical expressions to calculate the design distribution and to decode and code the ranges of the tested variables is presented in Table A1 (ESI $\dagger)$.

2.4.2 Mathematical model and responses used. The response surface models were fitted by means of least-squares calculation using the following second-order polynomial equation:

$$
Y=b_{0}+\sum_{i=1}^{n} b_{i} X_{i}+\sum_{\substack{i=1 \\ j>i}}^{n-1} \sum_{j=2}^{n} b_{i j} X_{i} X_{j}+\sum_{i=1}^{n} b_{i i} X_{i}^{2}
$$

where $Y$ is the dependent variable (response variable) to be modelled, $X_{i}$ and $X_{j}$ define the independent variables, $b_{0}$ is the constant coefficient, $b_{i}$ is the coefficient of linear effect, $b_{i j}$ is the coefficient of interaction effect, $b_{i i}$ is the coefficient of quadratic effect and $n$ is the number of variables. The dependent variable responses comprise: (1) the antibacterial criteria (MIC and $\mathrm{MBC}$, in $\mathrm{g} \mathrm{L}^{-1}$ ) for all the bacteria strains $\left(\mathrm{B}_{1-4}\right)$, and (2) the antifungal criteria (MIC and MFC, in $\mathrm{g} \mathrm{L}^{-1}$ ) for all fungal strains $\left(\mathrm{F}_{1-4}\right)$.

2.4.3 Procedure to optimize the variables to a maximum response. For response optimization, a maximization process was applied using a simple method to solve non-linear problems. ${ }^{31,32}$ Constraints were imposed to the variable coded values to avoid unnatural conditions (i.e., times lower than 0 ).

\subsection{Fitting procedures and statistical analysis}

Fitting procedures, coefficient estimates and statistical calculations were performed as previously described. ${ }^{33}$ In brief, (a) the coefficient measurement was performed using the nonlinear least-squares (quasi-Newton) method provided by the macro "Solver" in Microsoft Excel, ${ }^{34}$ which allows minimizing the sum of the quadratic differences between the observed and model-predicted values; (b) the coefficient significance was evaluated using the "SolverAid" to determine the parametric confidence intervals. ${ }^{35}$ The non-statistically significant terms ( $p$-value $>0.05$ ) were dropped to simplify the model; and (c) the model reliability was verified using the following criteria: (i) the Fisher $F$-test $(\alpha=0.05)$ was used to determine whether the constructed models were adequate to describe the observed data; (ii) the "SolverStat" macro was used for the assessment of parameter and model prediction uncertainties; ${ }^{36}$ and (iii) the $R^{2}$ was interpreted as the proportion of variability of the dependent variable explained by the model.

\section{Results and discussion}

\subsection{Optimization of the extraction of compounds by RSM for enhancing antimicrobial activity}

3.1.1 Development of the theoretical response surface models and statistical verification. Descriptive empirical mathematical models were developed to assist the comprehension of the potential cause of variation in the response, and to explain how much each factor contributes to that variation. ${ }^{34,37}$ This was achieved by statistically relating variation in the response variable to the variation in the explanatory variables, and obtaining the best fit by minimizing the deviations between the predicted and the actual response. ${ }^{37}$ Fitting the models for the selected responses is crucial to elucidate how precisely the second-order polynomial model with interactions of eqn (1) (standard model used in RSM analysis) can predict the ideal variances. The models for each response were built by fitting the model of eqn (1) (independent variables in coded values) to the experimental values (Table 1) through nonlinear least-squares estimations. The parametric coefficient values of the resulting models are statistically assessed to determine its significant or non-significant (ns) effect using the "SolverAid" and "SolverStat" macros in Microsoft Excel at a 95\% confidence level $(\alpha=0.05){ }^{35,36}$ Those that showed ns coefficient estimations are removed and the fitting procedure is restarted; afterwards the process is repeated until all the parameters show significant coefficient estimations $(\alpha=0.05)$. The final parametric values achieved for all experimental responses of Table 1 are presented in Table 2 . The parametric values translate the response patterns and show the complexity of the possible interactions between variables. Under RSM analysis, the obtained model coefficients (Table 2) are empirical and cannot be associated with physical or chemical significance. 


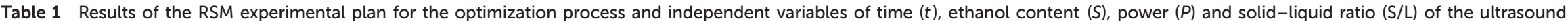

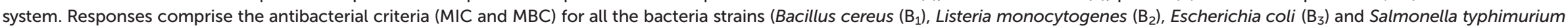
$\left(\mathrm{B}_{4}\right)$ ) and antifungal criteria (MIC and MFC) of all fungal strains (Aspergillus flavus $\left(\mathrm{F}_{1}\right)$, Aspergillus niger $\left(\mathrm{F}_{2}\right)$, Penicillium ochrochloron $\left(\mathrm{F}_{3}\right)$ and Penicillium verrucosum var. cyclopium $\left(\mathrm{F}_{4}\right)$ )

\begin{tabular}{|c|c|c|c|c|c|c|c|c|c|c|c|c|c|c|c|c|c|c|c|c|c|c|c|c|}
\hline & \multicolumn{8}{|c|}{ Experimental design } & \multicolumn{8}{|c|}{ Antibacterial activity } & \multicolumn{8}{|c|}{ Antifungal activity } \\
\hline & \multicolumn{4}{|c|}{ Coded values } & \multicolumn{4}{|c|}{ Natural values } & \multicolumn{4}{|l|}{ MIC } & \multicolumn{4}{|l|}{ MBC } & \multicolumn{4}{|l|}{ MIC } & \multicolumn{4}{|l|}{$\mathrm{MBC}$} \\
\hline & $X_{1}$ & $X_{2}$ & $X_{3}$ & $X_{4}$ & $\begin{array}{l}X_{1} t \\
\text { min }\end{array}$ & $\begin{array}{l}X_{2} \\
\mathrm{P}, \\
\mathrm{W}\end{array}$ & $\begin{array}{l}X_{3} \\
\mathrm{~S}, \\
\%\end{array}$ & $\begin{array}{l}X_{4} \mathrm{~S} / \mathrm{L} \\
\mathrm{g} \mathrm{L}^{-1}\end{array}$ & $\begin{array}{l}\mathrm{B}_{1}, \\
\mathrm{~g} \mathrm{~L} \mathrm{~L}^{-1}\end{array}$ & $\begin{array}{l}\mathrm{B}_{2}, \\
\mathrm{~g} \mathrm{~L}^{-1}\end{array}$ & $\begin{array}{l}\mathrm{B}_{3}, \\
\mathrm{~g} \mathrm{~L}^{-1}\end{array}$ & $\begin{array}{l}\mathrm{B}_{4}, \\
\mathrm{~g} \mathrm{~L}^{-1}\end{array}$ & $\begin{array}{l}\mathrm{B}_{1} \\
\mathrm{~g} \mathrm{~L}^{-1}\end{array}$ & $\begin{array}{l}\mathrm{B}_{2}, \\
\mathrm{~g} \mathrm{~L}^{-1}\end{array}$ & $\begin{array}{l}\mathrm{B}_{3}, \\
\mathrm{~g} \mathrm{~L}^{-1}\end{array}$ & $\begin{array}{l}\mathrm{B}_{4}, \\
\mathrm{~g} \mathrm{~L}^{-1}\end{array}$ & $\begin{array}{l}\mathrm{F}_{1}, \\
\mathrm{~g} \mathrm{~L}^{-1}\end{array}$ & $\begin{array}{l}\mathrm{F}_{2}, \\
\mathrm{~g} \mathrm{~L} \mathrm{~L}^{-1}\end{array}$ & $\begin{array}{l}\mathrm{F}_{3} \\
\mathrm{~g} \mathrm{~L}^{-1}\end{array}$ & $\begin{array}{l}\mathrm{F}_{4} \\
\mathrm{~g} \mathrm{~L} \mathrm{~L}^{-1}\end{array}$ & $\begin{array}{l}\mathrm{F}_{1}, \\
\mathrm{~g} \mathrm{~L} \mathrm{~L}^{-1}\end{array}$ & $\begin{array}{l}\mathrm{F}_{2}, \\
\mathrm{~g} \mathrm{~L}^{-1}\end{array}$ & $\begin{array}{l}\mathrm{F}_{3}, \\
\mathrm{~g} \mathrm{~L}^{-1}\end{array}$ & $\begin{array}{l}\mathrm{F}_{4}, \\
\mathrm{~g} \mathrm{~L}^{-1}\end{array}$ \\
\hline 1 & -1 & -1 & -1 & -1 & 7 & 200 & 25 & 15 & 0.3 & 0.4 & 0.3 & 0.3 & 0.5 & 0.8 & 0.5 & 0.5 & 0.5 & 0.4 & 0.3 & 0.3 & 0.7 & 1.4 & 0.4 & 0.6 \\
\hline 2 & 1 & -1 & -1 & -1 & 17 & 200 & 25 & 15 & 0.4 & 0.5 & 0.3 & 0.3 & 0.6 & 1.0 & 0.6 & 0.5 & 0.5 & 0.4 & 0.3 & 0.6 & 0.8 & 1.2 & 0.5 & 1.0 \\
\hline 3 & -1 & 1 & -1 & -1 & 7 & 400 & 25 & 15 & 0.3 & 0.4 & 0.3 & 0.4 & 0.4 & 0.7 & 0.5 & 0.5 & 0.4 & 0.4 & 0.3 & 0.3 & 0.7 & 1.6 & 0.4 & 0.6 \\
\hline 4 & 1 & 1 & -1 & -1 & 17 & 400 & 25 & 15 & 0.3 & 0.4 & 0.3 & 0.3 & 0.5 & 0.8 & 0.5 & 0.5 & 0.5 & 0.5 & 0.3 & 0.5 & 0.7 & 1.5 & 0.5 & 0.8 \\
\hline 5 & -1 & -1 & 1 & -1 & 7 & 200 & 75 & 15 & 0.3 & 0.3 & 0.3 & 0.3 & 0.4 & 1.1 & 0.6 & 0.5 & 0.5 & 0.3 & 0.4 & 0.5 & 0.7 & 1.3 & 0.6 & 1.0 \\
\hline 6 & 1 & -1 & 1 & -1 & 17 & 200 & 75 & 15 & 0.3 & 0.4 & 0.4 & 0.3 & 0.5 & 1.1 & 0.9 & 0.5 & 0.3 & 0.3 & 0.4 & 0.6 & 0.7 & 1.2 & 0.5 & 1.1 \\
\hline 7 & -1 & 1 & 1 & -1 & 7 & 400 & 75 & 15 & 0.3 & 0.4 & 0.3 & 0.4 & 0.4 & 0.7 & 0.4 & 0.5 & 0.4 & 0.4 & 0.5 & 0.5 & 0.8 & 1.1 & 0.7 & 0.9 \\
\hline 8 & 1 & 1 & 1 & -1 & 17 & 400 & 75 & 15 & 0.3 & 0.3 & 0.3 & 0.4 & 0.4 & 0.7 & 0.6 & 0.6 & 0.5 & 0.3 & 0.5 & 0.5 & 0.8 & 0.9 & 0.5 & 1.0 \\
\hline 9 & -1 & -1 & -1 & 1 & 7 & 200 & 25 & 35 & 0.4 & 0.4 & 0.3 & 0.4 & 0.6 & 0.7 & 0.7 & 0.5 & 0.5 & 0.5 & 0.3 & 0.2 & 0.9 & 1.4 & 0.3 & 0.6 \\
\hline 10 & 1 & -1 & -1 & 1 & 17 & 200 & 25 & 35 & 0.4 & 0.4 & 0.3 & 0.4 & 0.6 & 0.7 & 0.5 & 0.5 & 0.4 & 0.5 & 0.3 & 0.4 & 0.8 & 1.5 & 0.4 & 0.8 \\
\hline 11 & -1 & 1 & -1 & 1 & 7 & 400 & 25 & 35 & 0.6 & 0.6 & 0.5 & 0.3 & 0.8 & 1.1 & 1.0 & 0.5 & 0.8 & 1.0 & 0.5 & 0.5 & 1.3 & 2.5 & 0.7 & 1.1 \\
\hline 12 & 1 & 1 & -1 & 1 & 17 & 400 & 25 & 35 & 0.6 & 0.5 & 0.4 & 0.3 & 0.8 & 1.1 & 0.8 & 0.6 & 0.9 & 1.0 & 0.5 & 0.8 & 1.3 & 2.8 & 0.9 & 1.4 \\
\hline 13 & -1 & -1 & 1 & 1 & 7 & 200 & 75 & 35 & 0.4 & 0.3 & 0.5 & 0.4 & 0.7 & 1.1 & 0.8 & 0.5 & 0.6 & 0.6 & 0.6 & 0.6 & 1.0 & 1.7 & 1.0 & 1.0 \\
\hline 14 & 1 & -1 & 1 & 1 & 17 & 200 & 75 & 35 & 0.3 & 0.4 & 0.4 & 0.4 & 0.6 & 0.9 & 0.6 & 0.5 & 0.6 & 0.6 & 0.5 & 0.7 & 1.0 & 1.8 & 0.9 & 1.0 \\
\hline 15 & -1 & 1 & 1 & 1 & 7 & 400 & 75 & 35 & 0.5 & 0.5 & 0.5 & 0.4 & 0.8 & 1.2 & 0.8 & 0.6 & 0.9 & 0.8 & 0.9 & 0.9 & 1.2 & 1.8 & 1.4 & 1.4 \\
\hline 16 & 1 & 1 & 1 & 1 & 17 & 400 & 75 & 35 & 0.5 & 0.4 & 0.4 & 0.3 & 0.8 & 1.1 & 0.7 & 0.5 & 0.9 & 0.8 & 0.9 & 0.9 & 1.3 & 2.0 & 1.3 & 1.5 \\
\hline 17 & -2 & 0 & 0 & 0 & 2 & 300 & 50 & 25 & 0.5 & 0.4 & 0.3 & 0.5 & 0.7 & 0.8 & 0.6 & 0.6 & 0.8 & 0.7 & 0.4 & 0.5 & 1.0 & 1.8 & 0.5 & 0.9 \\
\hline 18 & 2 & 0 & 0 & 0 & 22 & 300 & 50 & 25 & 0.5 & 0.4 & 0.3 & 0.4 & 0.7 & 0.8 & 0.6 & 0.6 & 0.8 & 0.6 & 0.4 & 0.8 & 1.0 & 1.9 & 0.6 & 1.3 \\
\hline 19 & 0 & -2 & 0 & 0 & 12 & 100 & 50 & 25 & 0.3 & 0.5 & 0.4 & 0.3 & 0.5 & 1.0 & 0.9 & 0.4 & 0.4 & 0.5 & 0.3 & 0.4 & 1.0 & 1.6 & 0.8 & 0.8 \\
\hline 20 & 0 & 2 & 0 & 0 & 12 & 500 & 50 & 25 & 0.5 & 0.6 & 0.4 & 0.3 & 0.6 & 1.0 & 0.9 & 0.6 & 0.7 & 0.8 & 0.5 & 0.6 & 1.4 & 2.2 & 1.2 & 1.0 \\
\hline 21 & 0 & 0 & -2 & 0 & 12 & 300 & 0 & 25 & 0.4 & 0.5 & 0.5 & 0.4 & 0.6 & 1.0 & 0.8 & 0.6 & 0.7 & 0.7 & 0.5 & 0.6 & 1.2 & 1.6 & 0.6 & 1.1 \\
\hline 22 & 0 & 0 & 2 & 0 & 12 & 300 & 100 & 25 & 0.3 & 0.2 & 0.6 & 0.5 & 0.5 & 1.2 & 0.8 & 0.6 & 0.6 & 0.5 & 1.0 & 0.9 & 1.0 & 1.1 & 1.2 & 1.6 \\
\hline 23 & 0 & 0 & 0 & -2 & 12 & 300 & 50 & 5 & 0.2 & 0.3 & 0.2 & 0.3 & 0.4 & 0.8 & 0.4 & 0.6 & 0.3 & 0.2 & 0.3 & 0.3 & 0.5 & 1.0 & 0.3 & 0.7 \\
\hline 24 & 0 & 0 & 0 & 2 & 12 & 300 & 50 & 45 & 0.5 & 0.4 & 0.4 & 0.3 & 0.9 & 1.0 & 0.6 & 0.5 & 0.8 & 0.8 & 0.6 & 0.6 & 1.3 & 2.2 & 0.8 & 1.2 \\
\hline 25 & 0 & 0 & 0 & 0 & 12 & 300 & 50 & 25 & 0.3 & 0.3 & 0.3 & 0.3 & 0.5 & 0.8 & 0.5 & 0.4 & 0.4 & 0.3 & 0.4 & 0.5 & 0.8 & 1.2 & 0.5 & 0.9 \\
\hline 26 & 0 & 0 & 0 & 0 & 12 & 300 & 50 & 25 & 0.3 & 0.3 & 0.3 & 0.3 & 0.5 & 0.8 & 0.5 & 0.4 & 0.4 & 0.3 & 0.4 & 0.5 & 0.8 & 1.2 & 0.5 & 0.9 \\
\hline 27 & 0 & 0 & 0 & 0 & 12 & 300 & 50 & 25 & 0.3 & 0.3 & 0.3 & 0.3 & 0.5 & 0.8 & 0.5 & 0.4 & 0.4 & 0.3 & 0.4 & 0.5 & 0.8 & 1.2 & 0.5 & 0.9 \\
\hline 28 & 0 & 0 & 0 & 0 & 12 & 300 & 50 & 25 & 0.3 & 0.3 & 0.3 & 0.3 & 0.5 & 0.8 & 0.5 & 0.4 & 0.4 & 0.3 & 0.4 & 0.5 & 0.8 & 1.2 & 0.5 & 0.9 \\
\hline 29 & 0 & 0 & 0 & 0 & 12 & 300 & 50 & 25 & 0.3 & 0.3 & 0.3 & 0.3 & 0.5 & 0.8 & 0.5 & 0.4 & 0.4 & 0.3 & 0.4 & 0.5 & 0.8 & 1.2 & 0.5 & 0.9 \\
\hline 30 & 0 & 0 & 0 & 0 & 12 & 300 & 50 & 25 & 0.3 & 0.3 & 0.3 & 0.3 & 0.5 & 0.8 & 0.5 & 0.4 & 0.4 & 0.3 & 0.4 & 0.5 & 0.8 & 1.2 & 0.5 & 0.9 \\
\hline 31 & 0 & 0 & 0 & 0 & 12 & 300 & 50 & 25 & 0.3 & 0.3 & 0.3 & 0.3 & 0.5 & 0.8 & 0.5 & 0.4 & 0.4 & 0.3 & 0.4 & 0.5 & 0.8 & 1.2 & 0.5 & 0.9 \\
\hline 32 & 0 & 0 & 0 & 0 & 12 & 300 & 50 & 25 & 0.3 & 0.3 & 0.3 & 0.3 & 0.5 & 0.8 & 0.5 & 0.4 & 0.4 & 0.3 & 0.4 & 0.5 & 0.8 & 1.2 & 0.5 & 0.9 \\
\hline
\end{tabular}


Table 2 Estimated coefficient values obtained by the theoretical second order polynomial models of eqn (1), parametric intervals and numerical statistical criteria for each parametric response criteria of the antimicrobial activity tested. Responses comprise the antibacterial criteria (MIC and $\mathrm{MBC}$ ) for all the bacteria strains (Bacillus cereus $\left(\mathrm{B}_{1}\right)$, Listeria monocytogenes $\left(\mathrm{B}_{2}\right)$, Escherichia coli $\left(\mathrm{B}_{3}\right)$ and Salmonella typhimurium $\left(\mathrm{B}_{4}\right)$ ) and antifungal criteria (MIC and MFC) of all fungal strains (Aspergillus flavus $\left(\mathrm{F}_{1}\right)$, Aspergillus niger $\left(\mathrm{F}_{2}\right)$, Penicillium ochrochloron $\left(\mathrm{F}_{3}\right)$ and Penicillium verrucosum var. cyclopium $\left.\left(\mathrm{F}_{4}\right)\right)$

Antibacterial activity

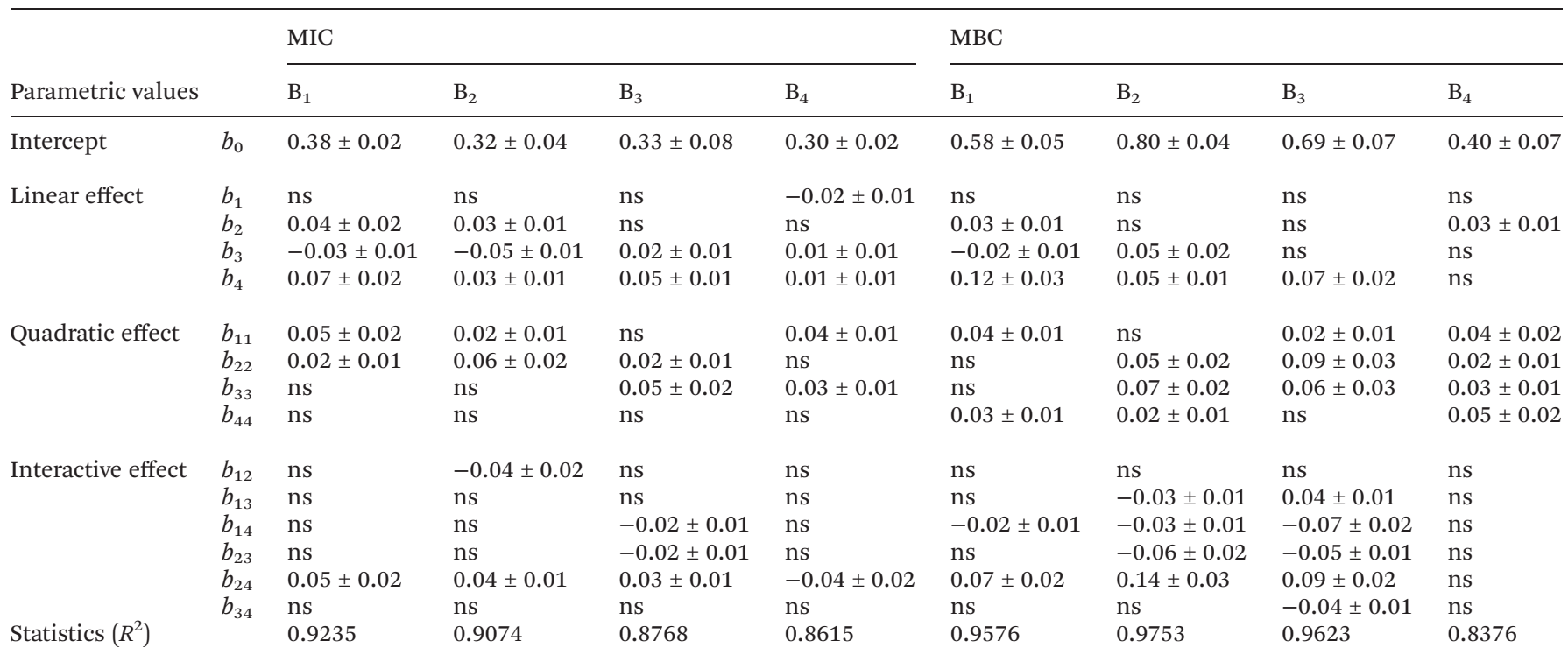

Antifungal activity

\begin{tabular}{|c|c|c|c|c|c|c|c|c|c|}
\hline \multirow[b]{2}{*}{ Parametric values } & & \multicolumn{4}{|l|}{ MIC } & \multicolumn{4}{|l|}{$\mathrm{MBC}$} \\
\hline & & $\mathrm{F}_{1}$ & $\mathrm{~F}_{2}$ & $\mathrm{~F}_{3}$ & $\mathrm{~F}_{4}$ & $\mathrm{~F}_{1}$ & $\mathrm{~F}_{2}$ & $\mathrm{~F}_{3}$ & $\mathrm{~F}_{4}$ \\
\hline Intercept & $b_{0}$ & $0.44 \pm 0.06$ & $0.30 \pm 0.07$ & $0.40 \pm 0.02$ & $0.55 \pm 0.04$ & $0.80 \pm 0.13$ & $1.82 \pm 0.13$ & $0.70 \pm 0.07$ & $1.07 \pm 0.08$ \\
\hline \multirow[t]{4}{*}{ Linear effect } & $b_{1}$ & ns & ns & ns & $0.07 \pm 0.02$ & ns & ns & ns & $0.09 \pm 0.02$ \\
\hline & $b_{2}$ & $0.08 \pm 0.04$ & $0.10 \pm 0.04$ & $0.07 \pm 0.02$ & $0.06 \pm 0.02$ & $0.10 \pm 0.03$ & $0.17 \pm 0.05$ & $0.11 \pm 0.05$ & $0.09 \pm 0.03$ \\
\hline & $b_{3}$ & ns & $-0.05 \pm 0.02$ & $0.11 \pm 0.02$ & $0.09 \pm 0.03$ & ns & $-0.15 \pm 0.05$ & $0.17 \pm 0.05$ & $0.11 \pm 0.02$ \\
\hline & $b_{4}$ & $0.13 \pm 0.04$ & $0.15 \pm 0.04$ & $0.09 \pm 0.02$ & $0.08 \pm 0.03$ & $0.19 \pm 0.05$ & $0.31 \pm 0.09$ & $0.16 \pm 0.05$ & $0.11 \pm 0.03$ \\
\hline \multirow[t]{4}{*}{ Quadratic effect } & $b_{11}$ & $0.09 \pm 0.03$ & $0.08 \pm 0.04$ & ns & $0.03 \pm 0.01$ & $0.03 \pm 0.01$ & $0.15 \pm 0.03$ & ns & $0.04 \pm 0.01$ \\
\hline & $b_{22}$ & $0.03 \pm 0.01$ & $0.08 \pm 0.04$ & ns & ns & $0.08 \pm 0.02$ & $0.17 \pm 0.03$ & $0.11 \pm 0.05$ & ns \\
\hline & $b_{33}$ & $0.05 \pm 0.02$ & $0.05 \pm 0.01$ & $0.07 \pm 0.02$ & $0.06 \pm 0.02$ & $0.05 \pm 0.02$ & ns & $0.09 \pm 0.05$ & $0.08 \pm 0.02$ \\
\hline & $b_{44}$ & $0.03 \pm 0.01$ & $0.06 \pm 0.02$ & ns & ns & ns & $0.09 \pm 0.02$ & ns & ns \\
\hline \multirow[t]{6}{*}{ Interactive effect } & $b_{12}$ & $0.04 \pm 0.02$ & ns & ns & ns & ns & ns & ns & ns \\
\hline & $b_{13}$ & ns & ns & ns & $-0.05 \pm 0.02$ & ns & ns & $-0.06 \pm 0.02$ & $-0.05 \pm 0.02$ \\
\hline & $b_{14}$ & ns & ns & ns & ns & ns & $0.09 \pm 0.01$ & ns & ns \\
\hline & $b_{23}$ & ns & $-0.03 \pm 0.01$ & $0.03 \pm 0.01$ & ns & ns & $-0.18 \pm 0.01$ & ns & ns \\
\hline & $b_{24}$ & $0.09 \pm 0.05$ & $0.08 \pm 0.03$ & $0.06 \pm 0.03$ & $0.09 \pm 0.03$ & $0.08 \pm 0.01$ & $0.18 \pm 0.01$ & $0.10 \pm 0.06$ & $0.15 \pm 0.03$ \\
\hline & $b_{34}$ & $0.04 \pm 0.01$ & ns & $0.04 \pm 0.02$ & $0.05 \pm 0.02$ & ns & ns & $0.11 \pm 0.06$ & ns \\
\hline Statistics $\left(R^{2}\right)$ & & 0.9482 & 0.9532 & 0.9734 & 0.9525 & 0.8954 & 0.9819 & 0.9755 & 0.9513 \\
\hline
\end{tabular}

However, they are useful for predicting the results of untested extraction conditions and for optimization procedures (maximization or minimization). ${ }^{38}$ The sign and the weight of the parametric value informs the effect and the performance of the response. In this way, when a factor has a positive effect, the response is higher at the high level, and when a factor has a negative effect, the response is lower at the high level. The higher the absolute value of a coefficient, the more important the weight of the corresponding variable. Next all mathematical models produced are presented.

For the antibacterial activity responses:

(a) when the analysis is performed in terms of the MIC responses:

$$
\begin{aligned}
Y_{\mathrm{B}_{1}}^{\mathrm{MIC}}= & 0.38+0.04 x_{2}-0.03 x_{3}+0.07 x_{4}+0.05 x_{1}{ }^{2} \\
& +0.02 x_{2}{ }^{2}+0.05 x_{2} x_{4}
\end{aligned}
$$




$$
\begin{aligned}
Y_{\mathrm{B}_{2}}^{\mathrm{MIC}}= & 0.32+0.03 x_{2}-0.05 x_{3}+0.03 x_{4}+0.02 x_{1}{ }^{2}+0.06 x_{2}{ }^{2} \\
& +0.04 x_{1} x_{2}+0.04 x_{2} x_{4}
\end{aligned}
$$

$$
\begin{aligned}
Y_{\mathrm{B}_{3}}^{\mathrm{MIC}}= & 0.33+0.02 x_{3}-0.05 x_{4}+0.02 x_{2}{ }^{2}+0.05 x_{3}{ }^{2}-0.02 x_{1} x_{4} \\
& -0.02 x_{2} x_{3}+0.03 x_{2} x_{4}
\end{aligned}
$$

$$
\begin{aligned}
Y_{\mathrm{B}_{4}}^{\mathrm{MIC}}= & 0.30+0.02 x_{1}+0.01 x_{3}+0.01 x_{4}+0.04 x_{1}{ }^{2}+0.03 x_{3}{ }^{2} \\
& -0.04 x_{2} x_{4}
\end{aligned}
$$

(b) when the analysis is performed in terms of the MBC responses:

$$
\begin{aligned}
Y_{\mathrm{B}_{1}}^{\mathrm{MBC}}= & 0.58+0.03 x_{2}+0.02 x_{3}+0.12 x_{4}+0.04 x_{1}{ }^{2}+0.03 x_{4}{ }^{2} \\
& -0.02 x_{1} x_{4}+0.07 x_{2} x_{4}
\end{aligned}
$$

$$
\begin{aligned}
Y_{\mathrm{B}_{2}}^{\mathrm{MBC}}= & 0.8+0.05 x_{3}+0.05 x_{4}+0.05 x_{2}{ }^{2}+0.07 x_{3}{ }^{2}-0.03 x_{1} x_{3} \\
& -0.03 x_{1} x_{4}-0.06 x_{2} x_{3}+0.14 x_{2} x_{4}
\end{aligned}
$$

$$
\begin{aligned}
Y_{\mathrm{B}_{3}}^{\mathrm{MBC}}= & 0.69+0.07 x_{4}+0.09 x_{4}{ }^{2}+0.06 x_{3}{ }^{2}+0.04 x_{1} x_{3}-0.07 x_{1} x_{4} \\
& -0.05 x_{2} x_{3}+0.09 x_{2} x_{4}+0.04 x_{3} x_{4}
\end{aligned}
$$

$$
Y_{\mathrm{B}_{4}}^{\mathrm{MBC}}=0.40+0.03 x_{2}+0.04 x_{1}{ }^{2}+0.02 x_{2}{ }^{2}+0.03 x_{3}{ }^{2}+0.05 x_{4}{ }^{2}
$$

For the antifungal activity responses:

(a) when the analysis is performed in terms of the MIC responses:

$$
\begin{aligned}
Y_{\mathrm{F}_{1}}^{\mathrm{MIC}}= & 0.44+0.08 x_{2}+0.13 x_{4}+0.09 x_{1}{ }^{2}+0.03 x_{2}{ }^{2}+0.05 x_{3}{ }^{2} \\
& +0.04 x_{1} x_{2}+0.09 x_{2} x_{4}+0.04 x_{3} x_{4}
\end{aligned}
$$$$
Y_{\mathrm{F}_{2}}^{\mathrm{MIC}}=0.3+0.1 x_{2}+0.05 x_{3}+0.15 x_{4}+0.08 x_{1}{ }^{2}+0.08 x_{2}{ }^{2}
$$$$
+0.05 x_{3}^{2}+0.06 x_{4}{ }^{2}-0.03 x_{2} x_{3}+0.08 x_{2} x_{4}
$$

$$
\begin{aligned}
Y_{\mathrm{F}_{3}}^{\mathrm{MIC}}= & 0.4+0.07 P x_{2}+0.11 x_{3}+0.09 x_{4}+0.07 x_{3}{ }^{2}+0.03 x_{2} x_{3} \\
& +0.06 x_{2} x_{4}+0.04 x_{3} x_{4}
\end{aligned}
$$

$$
\begin{aligned}
Y_{\mathrm{F}_{4}}^{\mathrm{MIC}}= & 0.55+0.07 x_{1}+0.06 x_{2}+0.09 x_{3}+0.08 x_{4}+0.06 x_{3}{ }^{2} \\
& -0.05 x_{1} x_{3}+0.09 x_{2} x_{4}+0.05 x_{3} x_{4}
\end{aligned}
$$

(b) when the analysis is performed in terms of the MFC responses:

$$
Y_{\mathrm{F}_{1}}^{\mathrm{MFC}}=0.8+0.1 x_{2}+0.19 x_{4}+0.03 x_{1}{ }^{2}+0.08 P x_{2}{ }^{2}+0.05 x_{3}{ }^{2}
$$

$$
\begin{aligned}
Y_{\mathrm{F}_{2}}^{\mathrm{MFC}}= & 1.82+0.17 x_{2}-0.15 x_{3}+0.31 x_{4}+0.15 x_{1}{ }^{2}+0.17 x_{2}{ }^{2} \\
& -0.09 x_{4}{ }^{2}+0.09 x_{1} x_{4}-0.18 x_{2} x_{3}+0.18 x_{2} x_{4}
\end{aligned}
$$

$$
\begin{aligned}
Y_{\mathrm{F}_{3}}^{\mathrm{MFC}}= & 0.7+0.11 x_{2}-0.17 x_{3}+0.16 x_{4}+0.11 x_{2}{ }^{2}+0.09 x_{3}{ }^{2} \\
& -0.06 x_{1} x_{3}+0.1 x_{2} x_{4}+0.11 x_{3} x_{4}
\end{aligned}
$$

$$
\begin{aligned}
Y_{\mathrm{F}_{4}}^{\mathrm{MFC}}= & 1.07+0.09 x_{1}+0.09 x_{2}+0.11 x_{3}+0.11 x_{4}+0.04 x_{1}{ }^{2} \\
& +0.08 x_{3}{ }^{2}-0.05 x_{1} x_{3}+0.15 x_{2} x_{4}
\end{aligned}
$$

where $X_{1}(t, \min ), X_{2}(P, \mathrm{~W}), X_{3}(S, \%)$ and $X_{4}\left(\mathrm{~S} / \mathrm{L}, \mathrm{g} \mathrm{L}^{-1}\right)$ are the variables, $Y$ is the response, sub-indices indicate the microbial strains used and the super-indices indicate the response criteria used to evaluate the results. The mathematical models of the antibacterial activity are displayed in eqn (2)-(5) for the MIC and eqn (6)-(9) for the MBC. Meanwhile, the mathematical models of the antifungal activity are displayed in eqn (10)-(13) for the MIC and eqn (14)-(17) for the MFC. Confidence intervals of the parametric values are presented in Table 2. For both types of antimicrobial responses (antibacterial and antifungal activity), the linear effect was the most significant one, followed closely by the quadratic and interactive effects.

In all cases, the statistical correlation coefficients $\left(R^{2}\right)$ proved to be a good agreement between the experimental results and the predicted patterns, showing values higher than 0.84 and in most of the cases showing values higher than 0.98 (Table 2). These workable models were applied in the subsequent prediction and optimization steps. In all cases, the MIC values showed lower response values than the MBC and MFC values.

3.1.2 Detailed description of one specific case to illustrate the analysis applied to evaluate the antibacterial and antifungal activity. Fig. 1 shows an illustration of a representative case to exemplify the procedure applied to enhance the antimicrobial activity of the extracts by optimizing the conditions of UAE using the RSM technique. The figure shows the results of the antifungal activity of Aspergillus niger $\left(\mathrm{F}_{2}\right)$ in terms of the MIC values obtained. Fig. 1 is divided into three separate parts (A, B and C) and each of them shows specific meaningful features of the response. By definition, the lower the MIC values the higher is the inhibitory activity; therefore, to display the responses in an informative and visual form, the axis of the results presented in Fig. 1 was inverted.

Part A of Fig. 1 shows the graphical analysis of the responses as a function of all variables assessed $\left(X_{1}\right.$ to $\left.X_{4}\right)$ in two different forms: (1) top diagonal part that shows the responses in a 3D format using surface plots, and (2) the bottom diagonal part that shows the $2 \mathrm{D}$ format using contour plots. The figures are produced with the polynomial model of eqn (11) that predicts the behavior of the responses displayed in Table 1 with $R^{2}=0.9532$. The model shows significant parametric values of linear, quadratic and interactive effects 


\section{A) GRAPHICAL ANALYSIS}

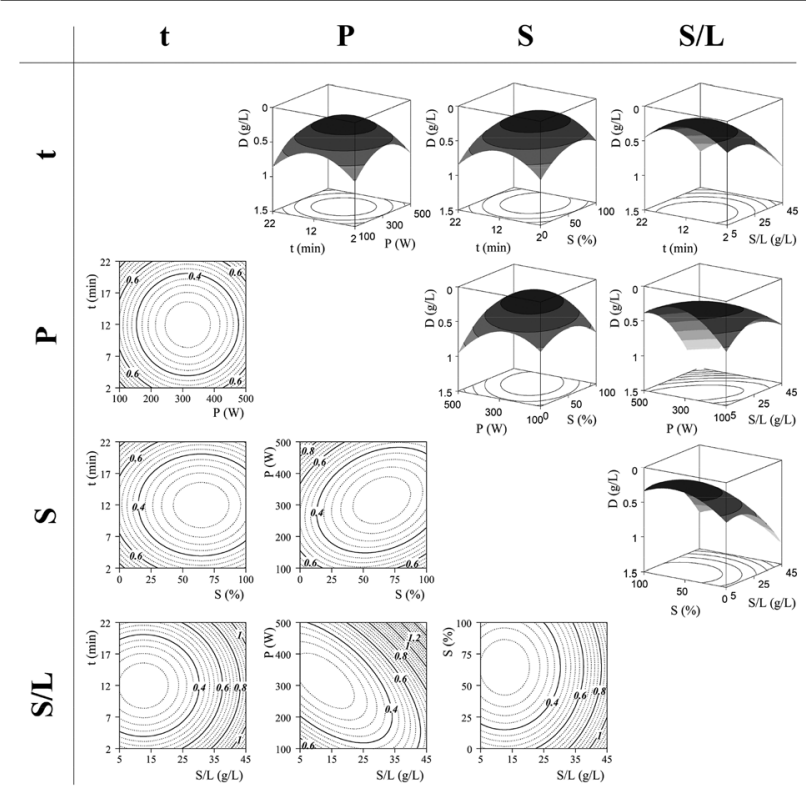

B) STATISTICAL ANALYSIS
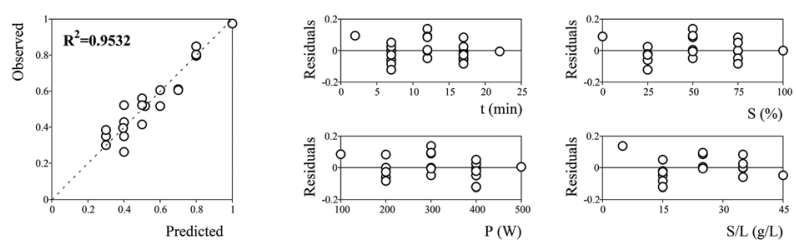

\section{C) OPTIMUM VALUES}

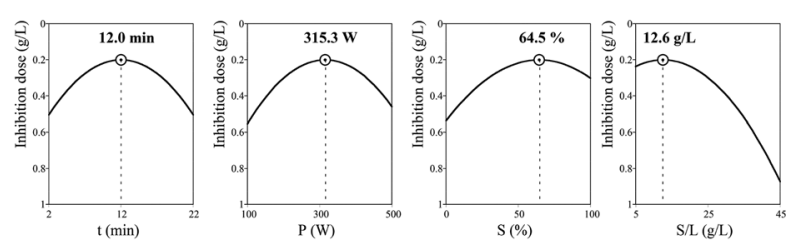

Fig. 1 Illustration of the procedure applied for the analysis of the antimicrobial responses of the UAE extracts obtained in the RSM experimental design applied. As a representative case, the figure shows the results of the antifungal activity in terms of the MIC of Aspergillus niger $\left(F_{2}\right)$. Part A: The graphical analysis of the responses as a function of all variables assessed in two different forms (top diagonal part shows the 3D surfaces and the bottom diagonal part shows the contour plots of the same responses). Note that the $Z$ axis of the 3D surfaces is inverted to display the results in an informative form. Part B: Illustration of the goodness of fit through two graphical statistical criteria, namely the ability to simulate response changes between the observed and predicted values and the residual distribution as a function of each variable. Part C: Individual responses as a function of all the variables assessed. The dots $(\odot)$ presented alongside each line highlight the location of the optimum value. Lines and dots are generated by the theoretical second order polynomial models of eqn (1). The variables in each of the graphs of part $A$ and $C$ were positioned at the optimal values of the others (Table 3). Note that the $Z$ axis of the 3D surfaces in part A and the $Y$ axis of the $2 \mathrm{D}$ graphs in part 3 are inverted to display the results in an informative form.
(Table 2). The non-significant parametric effects detected were the linear parametric value of $b_{1}$ (accounting for the effect of $t$ ) and the interactive parametric values of $b_{12}, b_{13}, b_{14}$ and $b_{34}$ (accounting for the effects of $t \times P, t \times S, t \times \mathrm{S} / \mathrm{L}$ and $S \times \mathrm{S} / \mathrm{L}$, respectively). Since the parametric values are expressed in coded values, the weight of each parameter represents, in comparative terms, the real influence of the response. The orders of the statistically significant parametric values as a function of their weight were as follows: $b_{4}(\mathrm{~S} / \mathrm{L}, 0.15) \gg b_{2}(P, 0.10)>$ $b_{11}\left(t^{2}, 0.08\right) \approx b_{22}\left(P^{2}, 0.08\right) \approx b_{24}(P \times \mathrm{S} / \mathrm{L}, 0.08)>b_{44}\left(\mathrm{~S} / \mathrm{L}^{2}\right.$, $0.06)>b_{33}\left(S^{2}, 0.05\right) \approx b_{3}(S,-0.05)>b_{23}(P \times S,-0.03)$. The relevance of the significant parametric values can be ordered as a function of the variables involved in a decreasing form as $\mathrm{S} / \mathrm{L}>P \gg S>t$. Part A of Fig. 1 shows that the UAE extracts have a relevant antifungal activity with low MIC values in a variety of different extraction conditions, generally at low $\mathrm{S} / \mathrm{L}$ values, and medium $t, P$ and $S$ values.

Part B of Fig. 1 illustrates the goodness of fit through two graphical statistical criteria. The first one shows the ability to simulate response changes between the observed and predicted values and, the second one shows the residual distribution as a function of each variable. These changes illustrate how precisely the predictions are given by the observed experimental responses. If this is true, then the relationship between the two can be summarized with a straight line. Such a linear relation can be evaluated through the coefficient of determination $R^{2}$, which in this illustrative case showed a value of 0.9532 , providing a measure of how well the observed outcomes are replicated by the multivariable model of eqn (11) applied. Regarding the graphical illustrations of the residual distribution, it is known that a residual value is the difference between the actual observed value and the predicted one. The smaller the residual values, the better the fitting procedure. In all cases, it can be perceived that the residual values obtained showed values lower than $\pm 5 \%$ of variance.

Finally, part C of Fig. 1 shows the individual responses of a function of all the variables assessed. Lines in each graph show the response pattern as a function of the variable assessed. The dots $(\odot)$ presented alongside each line highlight the location of the optimum value. Lines and dots are generated by the theoretical second order polynomial models of eqn (11). The optimum condition values that maximize the MIC response were $t=12.0 \mathrm{~min}, P=315.3 \mathrm{~W}, S=64.5 \%$ and $\mathrm{S} / \mathrm{L}=12.6 \mathrm{~g} \mathrm{~L}^{-1}$.

In consequence, once an example has been used as an illustrative case, in the following paragraphs all antimicrobial responses assessed described in Table 2 (antibacterial and antifungal) will be analyzed. Although the same analytical procedure was applied in all other responses, the illustrative material presented is simplified to the minimum graphical material.

3.1.3 Effects of the extraction variables on the response criteria that are used to evaluate the antibacterial activity and antifungal activity. The antibacterial responses MIC and MBC (Table 1) for all the bacteria strains $\left(B_{1-4}\right)$ analyzed are illus- 
trated in Fig. 2. The illustration is divided into two sections, one for the MIC results and another for the MBC ones. The representation of responses is made by $2 \mathrm{D}$ contour plots generated by the mathematical models of eqn (2)-(5) for the MIC and eqn (6)-(9) for the MBC. The obtained parametric fitting values and statistical coefficients are described in Table 2 . Linear, quadratic and interactive effects showed significant values, in which the quadratic effects showed the strongest relevance, and the interactive effects were the ones that has a reduced influence on the responses. These findings are characterized in the response illustration displayed in Fig. 2, for each bacteria strains $\left(\mathrm{B}_{1-4}\right)$ in terms of the MIC or MBC values. Each of the 6 counter plots generated for each bacteria strain involves two variables out of the four analyzed and one response, in which the other two variables were excluded, in each of the graphs, is positioned at the optimal values of the others (Table 3 ). The course of the maximization patterns is highlighted with trajectory lines to summarize and guide the interpretation of the figures. For the $\mathrm{B}_{1}$ strain the tendency shows nearly identical MIC and MBC responses, with maximization values of inhibition towards low $\mathrm{S} / \mathrm{L}$, medium $t$ and high $P$ and $S$. Meanwhile for the other strains $\left(\mathrm{B}_{2-4}\right)$ the responses are different, and only the $\mathrm{B}_{4}$ strain does not present uniformity between MBC and MIC tendencies.
The antifungal activity (in terms of MIC and MFC) of the fungus strains $\left(\mathrm{F}_{1-4}\right)$ was evaluated and the graphical illustration is presented in Fig. A1 (ESI $\dagger$ ). The analysis of Fig. A1 $\dagger$ is the same as in the antibacterial cases (Fig. 2). The mathematical models of the antifungal activity used are described in eqn (10)-(13) for the MIC and eqn (14)-(17) for the MFC and the full parametric information and its statistical results can be seen in Table 2 . As in the antibacterial cases the paramedic values that describe the antifungal activity show that the interactive effects continue to be those that are less frequently occurring, and the quadratic effects are those that present a stronger expression to characterize the growth inhibition, either in MIC or MFC responses. For all the strains assessed $\left(\mathrm{F}_{1-4}\right)$ the $\mathrm{MIC}$ and $\mathrm{MFC}$ responses show nearly similar patterns with a different dose level of response. The general tendencies show maximization values of inhibition towards low $\mathrm{S} / \mathrm{L}$, medium $S$, medium-high $t$ and high $P$.

\subsection{Optimal extraction conditions for maximizing the response criteria}

By applying a simplex algorithm methodology to solve nonlinear problems, the optimum individual, relative and global

\section{MIC}
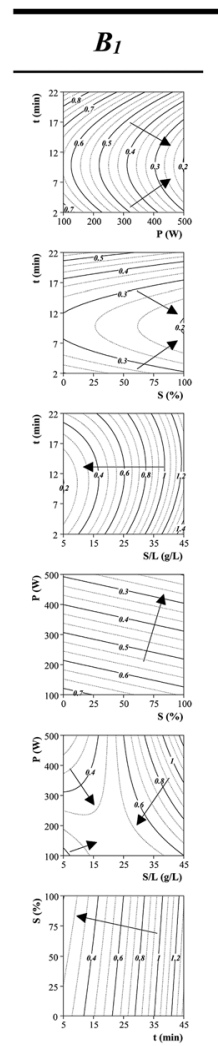
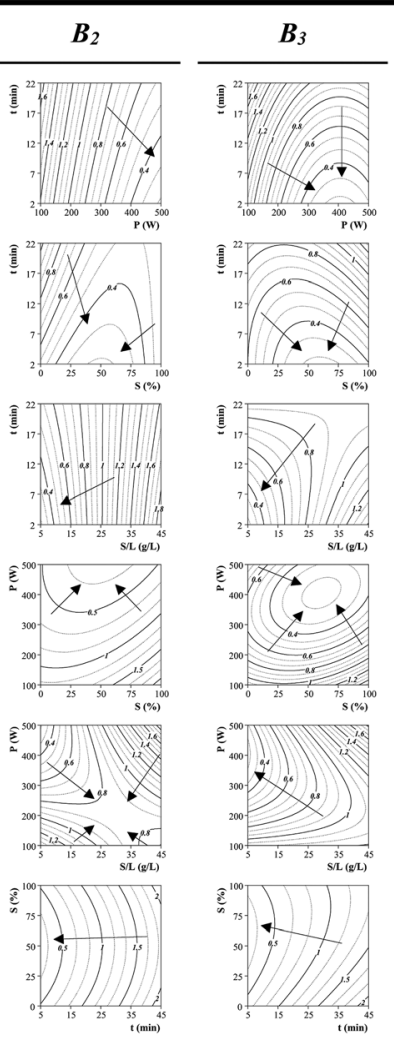
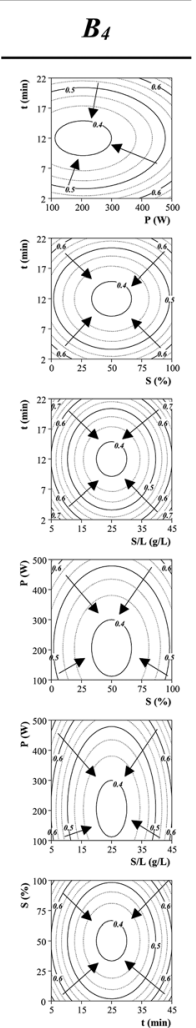

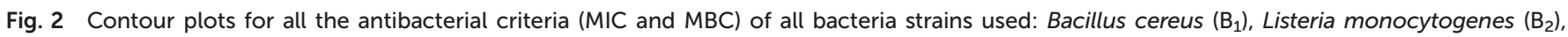

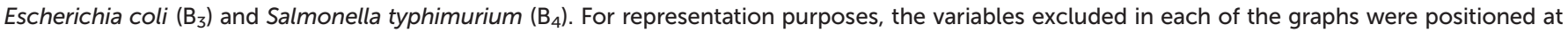
the optimal values of the others (Table 3). The obtained parametric fitting values are presented in Table 2. 
Table 3 Operating conditions that maximize the extraction of compounds with antimicrobial activity from Gomphrena globosa and optimal response values for all the parametric response criteria. Responses comprise the antibacterial criteria (MIC and MBC) for all the bacteria strains (Bacillus cereus $\left(B_{1}\right)$, Listeria monocytogenes $\left(B_{2}\right)$, Escherichia coli $\left(B_{3}\right)$ and Salmonella typhimurium $\left.\left(\mathrm{B}_{4}\right)\right)$ and antifungal criteria (MIC and MFC) of all fungal strains (Aspergillus flavus $\left(F_{1}\right)$, Aspergillus niger $\left(F_{2}\right)$, Penicillium ochrochloron $\left(F_{3}\right)$ and Penicillium verrucosum var. cyclopium $\left.\left(\mathrm{F}_{4}\right)\right)$

Optimal extraction conditions

$X_{1}: t \quad X_{2}: \mathrm{P} \quad X_{3}: \mathrm{S} \quad X_{4}: \mathrm{S} / \mathrm{L} \quad$ Response

(min) (W) $\quad(\%) \quad\left(\mathrm{g} \mathrm{L}^{-1}\right) \quad$ optimum

\begin{tabular}{|c|c|c|c|c|c|}
\hline \multicolumn{3}{|c|}{ Individual optimal responses } & \multicolumn{3}{|c|}{ Antibacterial activity } \\
\hline $\mathrm{MIC}_{\mathrm{B}_{1}}$ & 12.0 & 446.6 & 100.0 & 5.0 & $0.125 \pm 0.019 \mathrm{~g} \mathrm{~L}^{-1}$ \\
\hline $\mathrm{MIC}_{\mathrm{B}_{2}}$ & 14.3 & 357.1 & 100.0 & 5.0 & $0.148 \pm 0.018 \mathrm{~g} \mathrm{~L}^{-1}$ \\
\hline $\mathrm{MIC}_{\mathrm{B}_{3}}$ & 2.0 & 435.0 & 52.8 & 5.0 & $0.097 \pm 0.014 \mathrm{~g} \mathrm{~L}^{-1}$ \\
\hline $\mathrm{MIC}_{\mathrm{B}_{4}}$ & 13.3 & 100.0 & 44.3 & 5.0 & $0.113 \pm 0.004 \mathrm{~g} \mathrm{~L}^{-1}$ \\
\hline $\mathrm{MBC}_{\mathrm{B}_{1}}$ & 9.9 & 500.0 & 100.0 & 5.0 & $0.197 \pm 0.033 \mathrm{~g} \mathrm{~L}^{-1}$ \\
\hline $\mathrm{MBC}_{\mathrm{B}_{2}}$ & 2.0 & 500.0 & 49.6 & 5.0 & $0.254 \pm 0.042 \mathrm{~g} \mathrm{~L}^{-1}$ \\
\hline $\mathrm{MBC}_{\mathrm{B}}$ & 2.0 & 405.6 & 60.8 & 5.0 & $0.244 \pm 0.033 \mathrm{~g} \mathrm{~L}^{-1}$ \\
\hline $\mathrm{MBC}_{\mathrm{B}_{4}}$ & 12.0 & 205.9 & 50.0 & 25.0 & $0.386 \pm 0.027 \mathrm{~g} \mathrm{~L}^{-1}$ \\
\hline \multicolumn{6}{|c|}{ Antifungal activity } \\
\hline $\mathrm{MIC}_{\mathrm{F}_{1}}$ & 9.8 & 495.1 & 68.4 & 5.0 & $0.180 \pm 0.030 \mathrm{~g} \mathrm{~L}^{-1}$ \\
\hline $\mathrm{MIC}_{\mathrm{F}_{2}}$ & 12.0 & 315.3 & 64.5 & 12.6 & $0.201 \pm 0.021 \mathrm{~g} \mathrm{~L}^{-1}$ \\
\hline $\mathrm{MIC}_{\mathrm{F}_{3}}$ & 16.4 & 500.0 & 32.5 & 5.0 & $0.102 \pm 0.017 \mathrm{~g} \mathrm{~L}^{-1}$ \\
\hline $\mathrm{MIC}_{\mathrm{F}}$ & 4.1 & 500.0 & 34.7 & 5.0 & $0.131 \pm 0.019 \mathrm{~g} \mathrm{~L}^{-1}$ \\
\hline $\mathrm{MFC}_{\mathrm{F}_{1}}$ & 12.0 & 345.0 & 50.0 & 5.0 & $0.414 \pm 0.048 \mathrm{~g} \mathrm{~L}^{-1}$ \\
\hline $\mathrm{MFC}_{\mathrm{F}_{2}}$ & 15.0 & 467.4 & 100.0 & 5.0 & $0.728 \pm 0.113 \mathrm{~g} \mathrm{~L}^{-1}$ \\
\hline $\mathrm{MFC}_{\mathrm{F}_{3}}$ & 22.0 & 340.2 & 76.2 & 5.0 & $0.273 \pm 0.031 \mathrm{~g} \mathrm{~L}^{-1}$ \\
\hline $\mathrm{MFC}_{\mathrm{F}}$ & 2.3 & 500.0 & 19.0 & 5.0 & $0.245 \pm 0.041 \mathrm{~g} \mathrm{~L}^{-1}$ \\
\hline
\end{tabular}

Relative optimal responses Antibacterial activity

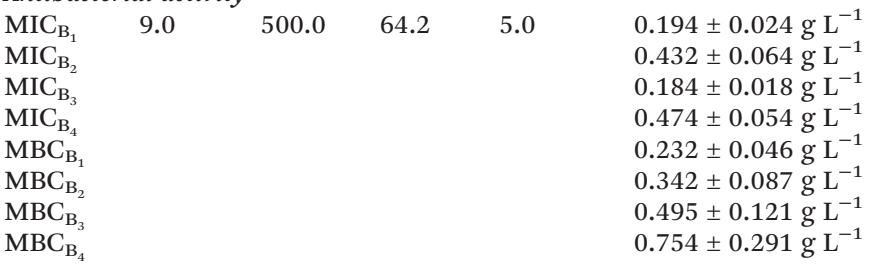

Antifungal activity

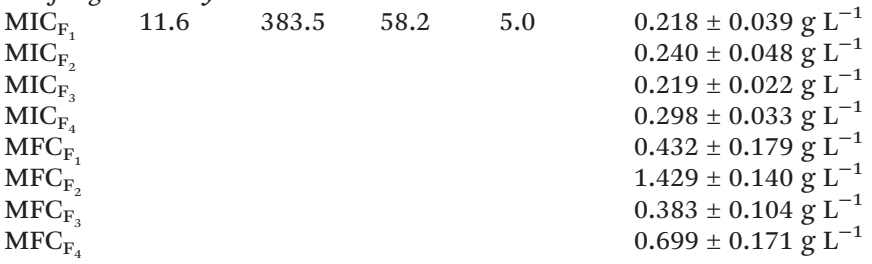

Global optimal responses

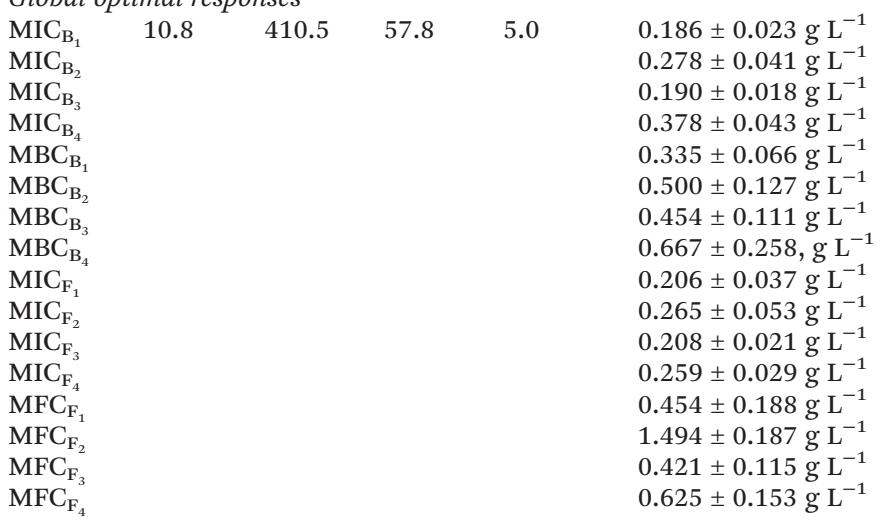

conditions for maximizing the antimicrobial activity (in terms of MIC and MBC or MFC) were determined. Fig. 3 and Table 3 show the patterns and numerical values of the variable conditions that maximize the responses assessed.

Table 3 presents the optimal operation values for the individual, relative and global maximization purposes of the antimicrobial activity (in terms of MIC and MBC or MFC). In the first part of Table 3 the optimal individual responses (MIC and MBC or MFC) to the tested bacteria and fungi strains are displayed. Thus, in the second part of Table 3, the relative operating conditions that maximize the MIC and MBC or MFC responses for the bacteria and fungi strains studied are presented. Finally, in the third part of Table 3 the optimal global conditions that maximize all responses are shown.

More specifically, Fig. 3 shows the 2D individual response patterns as a function of all the variables assessed for the antibacterial strains $\left(\mathrm{B}_{1-4}\right.$, under MIC and MBC criteria) and antifungal strains ( $\mathrm{F}_{1-4}$, under $\mathrm{MIC}$ and $\mathrm{MBC}$ criteria). The variables in each of the $2 \mathrm{D}$ graphs were positioned at the optimal values (Table 3 ) and the dots $(\odot)$ presented alongside each line highlight the location of the optimum value. The lines and dots are generated by the theoretical second order polynomial models of eqn (1).

Antimicrobial results (Fig. 3 and Table 3), either in terms of inhibition (MIC) or bactericidal/fungicidal activity (MBC or MFC) show low values of $\mathrm{S} / \mathrm{L}$, medium-low values of $t$, medium values of $S$ and high values of $P$. Except for power, which shows that higher potency values may be required to increase the antibacterial activity, all other results seem to be as planned in the RSM, within the variable range used. In fact, most of the responses were optimized, finding clear optimal values in the centre of the experimental design proposed. Such results have been found in previous studies, ${ }^{39}$ in which the authors found that strong energies in UAE may improve the extraction efficiency by increasing the extraction of compounds from active sites of the plant matrix used, due to the improvement of the solvent penetration and disruption of the cell membranes. The UAE global optimal condition results were $10.8 \mathrm{~min}, 410.5 \mathrm{~W}, 57.8 \%$ of ethanol and $5 \mathrm{~g}$ $\mathrm{L}^{-1}$ of the solid-liquid ratio providing the following response values: (1) from the studied bacteria species, the MIC ranged from $\sim 0.15$ to $0.35 \mathrm{~g} \mathrm{~L}^{-1}$ and regarding its $\mathrm{MBC}$ the ranges were $\sim 0.30$ to $0.65 \mathrm{~g} \mathrm{~L}^{-1}$; and (2) from the studied fungus species, the MIC ranged from $\sim 0.20$ to $0.30 \mathrm{~g} \mathrm{~L}^{-1}$ and regarding its MFC the ranges were $\sim 0.40$ to $0.65 \mathrm{~g} \mathrm{~L}^{-1}$. The antibacterial activity dose levels were lower than the antifungal ones.

UAE is an eco-friendly alternative to conventional techniques. The findings of this work are in accordance with the ones of Tomšik et al. ${ }^{40}$ which stated that UAE enhances the extraction process by increasing the mass transfer between the solvent and the plant material. The main benefits are the time and energy reduction, and type of applied solvents, consequently minimizing industrial emissions, ${ }^{41}$ which is an objective of the sustainable "green" chemistry. The collision of cavi- 
ANTIBACTERIAL ACTIVITY

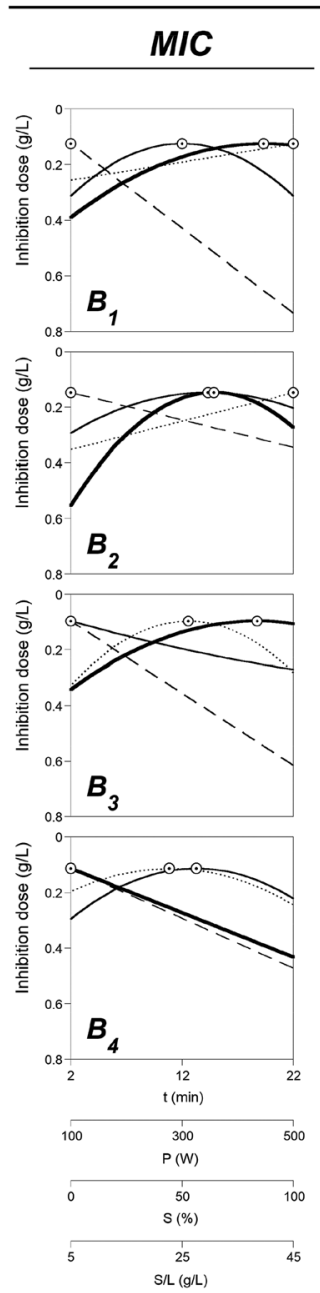

$M B C$
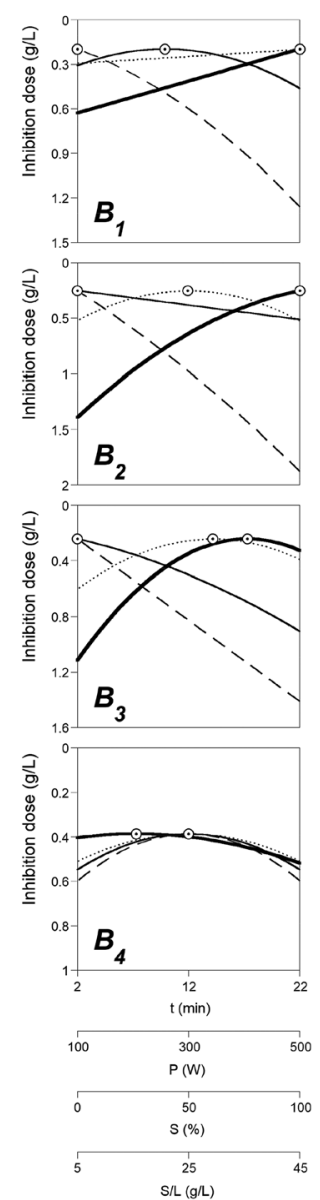

ANTIFUNGAL ACTIVITY

MIC
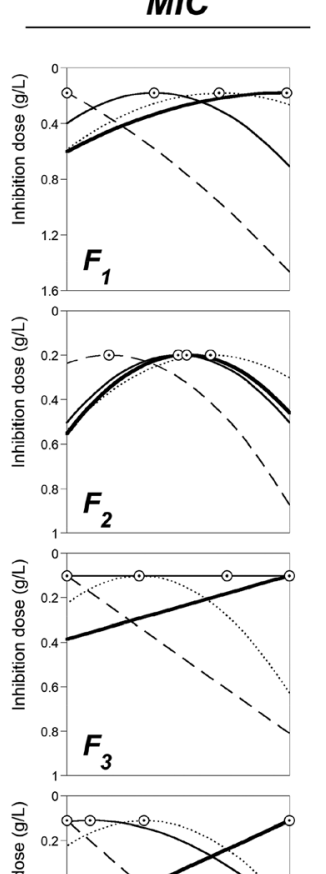

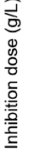

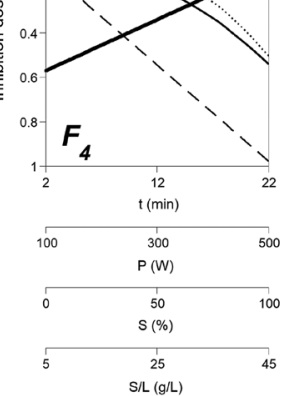

MFC

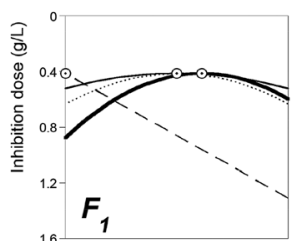

$F_{1}$

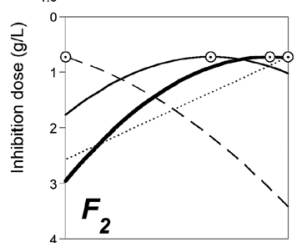

$F^{2}$
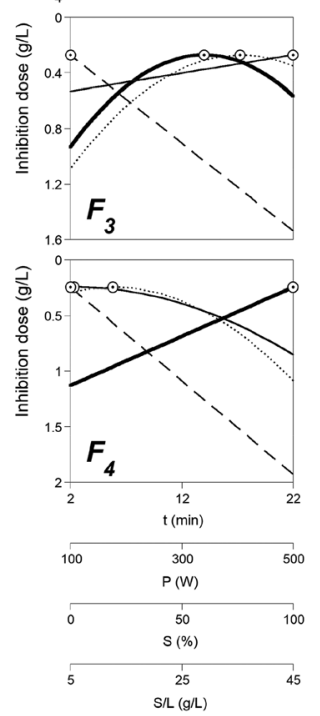

$-\operatorname{Time}(\min ) \quad$ Power (W)

Fig. 3 Individual response criteria as a function of all the variables assessed. Responses comprise the antibacterial criteria (MIC and $M B C$ ) for all the bacteria strains (Bacillus cereus $\left(\mathrm{B}_{1}\right)$, Listeria monocytogenes $\left(\mathrm{B}_{2}\right)$, Escherichia coli $\left(\mathrm{B}_{3}\right)$ and Salmonella typhimurium $\left(\mathrm{B}_{4}\right)$ ) and antifungal criteria $(\mathrm{MIC}$ and MFC) of all fungal strains (Aspergillus flavus $\left(\mathrm{F}_{1}\right)$, Aspergillus niger $\left(\mathrm{F}_{2}\right)$, Penicillium ochrochloron $\left(\mathrm{F}_{3}\right)$ and Penicillium verrucosum var. cyclopium $\left.\left(F_{4}\right)\right)$. The variables in each of the 2D graphs were positioned at the optimal values of the others (Table 3$)$. The dots $(\odot)$ presented alongside each line highlight the location of the optimum value. Lines and dots are generated by the theoretical second order polynomial models of eqn (1).

tation bubbles leads to a better cell disruption facilitating the release of extractable compounds, allowing a greater penetration of the solvent into the sample matrix, thus increasing the contact surface area between the solid and liquid phase. ${ }^{40,41}$ The results herein obtained are in accordance with conclusions previously found. ${ }^{41-43}$

\subsection{Industrial relevance}

The antimicrobial dose-level activity of the extracts is one of the most effective techniques for preserving the phytochemical composition and bioactive properties at the industrial level, to assure quality and reduce losses associated with microbial contamination. For the different industrial sectors, the use of suitable treatments is critical to obtain high quality products.

In this regard, different compounds/extracts with antimicrobial properties have been used as food additives to prevent deterioration processes. ${ }^{44}$ However, due to the limitation of the use of artificial compounds and enhanced public awareness of health issues, there is an increasing need to develop and use health-promoting natural ingredients in foods with antimicrobial properties. ${ }^{45}$ Despite the antimicrobial activity of the extracts being much lower compared with the evaluated commercial artificial ones, it is important to note that the extracts from $G$. globosa are a natural alternative colorant composed of different biomolecules, while the commercial antimicrobials are isolated pure compounds. 
Based on these optimized processing parameters it is possible to produce a food colorant ingredient with antimicrobial properties and thus add value to G. globosa extracts.

\section{Conclusions}

There is a current trend toward consuming more natural and healthier products at the expense of the counterparts with artificial additives. Thus, some studies are focused on finding new natural components that have a similar or better effect than artificial additives that also maintain the food quality and extend the shelf life, without changing the sensory characteristics of the products. There is a wide diversity of natural pigments that can be exploited for their incorporation into foods as colorants providing a variety of bioactive properties important for industrial applications. Recent studies have also shown that a diverse diet based on natural pigments present in fruits and vegetables is capable of acting as an antibacterial and antifungal agent.

The aim of this study was to evaluate the antimicrobial activity of extracts obtained from G. globosa, with the support of the RSM adapted to the UAE. The required extraction time was $10.8 \mathrm{~min}$, the power was $410.5 \mathrm{~W}$, with a percentage of ethanol of $57.8 \%$, and the solid-liquid ratio was $5 \mathrm{~g} \mathrm{~L}^{-1}$. In general, all responses were optimized, finding clear optimal values in the centre of the experimental design proposed. Although the UAE was conducted at strong energies, increased power values may improve the extraction efficiency of the compounds with antimicrobial potential from G. globosa flowers.

Thus, we have provided evidence that the extracts obtained from $G$. globosa that contain betacyanins, if used as natural colorants, would also retard microbial contamination, and therefore reduce the onset of spoilage. In addition to these favorable features, small quantities would be required for this effect. Therefore, these extracts could be considered as a good alternative to be applied in the food industry as natural colorants and preservative ingredients.

\section{Conflicts of interest}

The authors declare that no conflict of interest exists.

\section{Acknowledgements}

The authors thank the Foundation for Science and Technology (FCT, Portugal) and FEDER under Programme PT2020 for financial support to CIMO (UID/AGR/00690/2013) and L. Barros contract and C. L. Roriz (SFRH/BD/117995/2016) grant. This work was also funded by the European Regional Development Fund (ERDF) through the Regional Operational Program North 2020, within the scope of Project NORTE-010145-FEDER-023289: DeCodE and project Mobilizador Norte01-0247-FEDER-024479: ValorNatural@. The authors thank the GAIN (Xunta de Galicia) for financial support (P.P. $0000421 \mathrm{~S}$
140.08) to M. A. Prieto by a post-doctoral (modality B) grant. The authors also thank Ana Maria Carvalho for the plant donation.

\section{References}

1 M. R. Ammer, S. Zaman, M. Khalid, M. Bilal, S. Erum, D. Huang and S. Che, Optimization of Antibacterial Activity of Eucalyptus Tereticornis Leaf Extracts against Escherichia Coli through Response Surface Methodology, J. Radiat. Res. Appl. Sci., 2016, 9, 376-385.

2 World Health Organization, World Health Statistics 2017: Monitoring Health for The SDGs, 2017.

3 G. M. Cragg and D. J. Newman, Natural Products: A Continuing Source of Novel Drug Leads, Biochim. Biophys. Acta, Gen. Subj., 2013, 1830, 3670-3695.

4 H. J. Dorman and S. G. Deans, Antimicrobial Agents from Plants: Antibacterial Activity of Plant Volatile Oils, J. Appl. Microbiol., 2000, 88, 308-316.

5 B. Tepe, D. Daferera, A. Sokmen, M. Sokmen and M. Polissiou, Antimicrobial and Antioxidative Activities of the Essential Oils and Various Extracts of Salvia Tomentosa Miller (Lamiaceae), Food Chem., 2005, 90, 333-340.

6 J. Jacob, R. U. Rajendran, S. H. Priya, J. Purushothaman and D. K. B. N. Saraswathy Amma, Enhanced Antibacterial Metabolite Production through the Application of Statistical Methodologies by a Streptomyces Nogalater NIIST A30 Isolated from Western Ghats Forest Soil, PLoS One, 2017, 12, e0175919.

7 J. Pinela, L. Barros, A. M. Carvalho and I. C. F. R. Ferreira, Influence of the Drying Method in the Antioxidant Potential and Chemical Composition of Four Shrubby Flowering Plants from the Tribe Genisteae (Fabaceae), Food Chem. Toxicol., 2011, 49, 2983-2989.

8 I. Ihsanullah and A. Rashid, Current Activities in Food Irradiation as a Sanitary and Phytosanitary Treatment in the Asia and the Pacific Region and a Comparison with Advanced Countries, Food Control, 2017, 72, 345-359.

9 J. Pinela, L. Barros, M. Dueñas, A. M. Carvalho, C. SantosBuelga and I. C. F. R. Ferreira, Antioxidant Activity, Ascorbic Acid, Phenolic Compounds and Sugars of Wild and Commercial Tuberaria Lignosa Samples: Effects of Drying and Oral Preparation Methods, Food Chem., 2012, 135, 1028-1035.

10 G. C. Tenore, E. Novellino and A. Basile, Nutraceutical Potential and Antioxidant Benefits of Red Pitaya (Hylocereus Polyrhizus) Extracts, J. Funct. Foods, 2012, 4, 129-136.

11 J. M. Gostner, K. Becker, F. Ueberall and D. Fuchs, The Good and Bad of Antioxidant Foods: An Immunological Perspective, Food Chem. Toxicol., 2015, 80, 72-79.

12 F. Fathordoobady, H. Mirhosseini, J. Selamat and M. Y. A. Manap, Effect of Solvent Type and Ratio on Betacyanins and Antioxidant Activity of Extracts from Hylocereus Polyrhizus Flesh and Peel by Supercritical Fluid 
Extraction and Solvent Extraction, Food Chem., 2016, 202, 70-80.

13 L. C. P. Gonçalves, M. A. D. S. Trassi, N. B. Lopes, F. A. Dörr, M. T. dos Santos, W. J. Baader, V. X. Oliveira Jr. and E. L. Bastos, A Comparative Study of the Purification of Betanin, Food Chem., 2012, 131, 231-238.

14 A. Faridah, R. Holinesti and D. Syukri, Betalains from Red Pitaya Peel (Hylocereus Polyrhizus): Extraction, Spectrophotometric and HPLC-DAD Identification, Bioactivity and Toxicity Screening, Pak. J. Nutr., 2015, 14, 976-982.

15 B. Melgar, M. I. Dias, A. Ciric, M. Sokovic, E. M. GarciaCastello, A. D. Rodriguez-Lopez, L. Barros and I. Ferreira, By-Product Recovery of Opuntia Spp. Peels: Betalainic and Phenolic Profiles and Bioactive Properties, Ind. Crops Prod., 2017, 107, 353-359.

16 O. Osorio-Esquivel, A. Ortíz-Moreno, V. B. Álvarez, L. Dorantes-Álvarez and M. M. Giusti, Phenolics, Betacyanins and Antioxidant Activity in Opuntia Joconostle Fruits, Food Res. Int., 2011, 44, 2160-2168.

17 P. Morales, E. Ramírez-Moreno, M. de C. Sanchez-Mata, A. M. Carvalho and I. C. F. R. Ferreira, Nutritional and Antioxidant Properties of Pulp and Seeds of Two Xoconostle Cultivars (Opuntia Joconostle F.A.C. Weber Ex Diguet and Opuntia Matudae Scheinvar) of High Consumption in Mexico, Food Res. Int., 2012, 46, 279-285.

18 M. I. Khan, P. S. C. Sri Harsha, P. Giridhar and G. A. Ravishankar, Pigment Identification, Nutritional Composition, Bioactivity, and in Vitro Cancer Cell Cytotoxicity of Rivina Humilis L. Berries, Potential Source of Betalains, LWT-Food Sci. Technol., 2012, 47, 315-323.

19 N. Martins, C. L. Roriz, P. Morales, L. Barros and I. C. F. R. Ferreira, Food Colorants: Challenges, Opportunities and Current Desires of Agro-Industries to Ensure Consumer Expectations and Regulatory Practices, Trends Food Sci. Technol., 2016, 52, 1-15.

20 C. L. Roriz, L. Barros, A. M. Carvalho, C. Santos-Buelga and I. C. F. R. Ferreira, Pterospartum Tridentatum, Gomphrena Globosa and Cymbopogon Citratus: A Phytochemical Study Focused on Antioxidant Compounds, Food Res. Int., 2014, 62, 684-693.

21 C. L. Roriz, L. Barros, M. A. Prieto, P. Morales and I. C. F. R. Ferreira, Floral Parts of Gomphrena Globosa L. as a Novel Alternative Source of Betacyanins: Optimization of the Extraction Using Response Surface Methodology, Food Chem., 2017, 229, 223-234.

22 C. Jiménez L., C. Caleja, M. A. Prieto, M. F. Barreiro, L. Barros and I. C. F. R. Ferreira, Optimization and Comparison of Heat and Ultrasound Assisted Extraction Techniques to Obtain Anthocyanin Compounds from Arbutus Unedo L. Fruits, Food Chem., 2018, 264, 81-91.

23 C. Caleja, L. Barros, M. A. Prieto, F. M. F. Barreiro, M. B. P. Oliveira and I. C. F. R. Ferreira, Extraction of Rosmarinic Acid from Melissa Officinalis L. by Heat-, Microwave- and Ultrasound-Assisted Extraction Techniques: A Comparative Study through Response Surface Analysis, Sep. Purif. Technol., 2017, 186, 297-308.
24 N. Martins, C. L. Roriz, P. Morales, L. Barros and I. C. F. R. Ferreira, Coloring Attributes of Betalains: A Key Emphasis on Stability and Future Applications, Food Funct., 2017, 19-23.

25 J. Pinela, M. A. Prieto, L. Barros, A. M. Carvalho, M. B. P. P. Oliveira, J. A. Saraiva and I. C. F. R. Ferreira, Cold Extraction of Phenolic Compounds from Watercress by High Hydrostatic Pressure: Process Modelling and Optimization, Sep. Purif. Technol., 2018, 192, 501-512.

26 C. L. Roriz, L. Barros, M. A. Prieto, M. F. Barreiro, P. Morales and I. C. F. R. Ferreira, Modern Extraction Techniques Optimized to Extract Betacyanins from Gomphrena Globosa L, Ind. Crops Prod., 2017, 105, 2940.

27 M. Soković, J. Glamočlija, P. D. Marin, D. Brkić and L. J. L. D. van Griensven, Antibacterial Effects of the Essential Oils of Commonly Consumed Medicinal Herbs Using an In Vitro Model, Molecules, 2010, 15, 7532-7546.

28 M. Soković and L. J. L. D. van Griensven, Antimicrobial Activity of Essential Oils and Their Components against the Three Major Pathogens of the Cultivated Button Mushroom, Agaricus Bisporus, Eur. J. Plant Pathol., 2006, 116, 211-224.

29 S. A. Heleno, I. C. F. R. Ferreira, A. P. Esteves, A. Ćirić, J. Glamočlija, A. Martins, M. Soković and M. J. R. P. Queiroz, Antimicrobial and Demelanizing Activity of Ganoderma Lucidum Extract, p-Hydroxybenzoic and Cinnamic Acids and Their Synthetic Acetylated Glucuronide Methyl Esters, Food Chem. Toxicol., 2013, 58, 95-100.

30 G. Box and J. Hunter, Multi-Factor Experimental Designs for Exploring Response Surfaces, Ann. Math. Stat., 1957, 28, 195-241.

31 J. Pinela, M. A. Prieto, M. F. Barreiro, A. M. Carvalho, M. B. P. P. Oliveira, J. A. Vázquez and I. C. F. R. Ferreira, Optimization of Microwave-Assisted Extraction of Hydrophilic and Lipophilic Antioxidants from a Surplus Tomato Crop by Response Surface Methodology, Food Bioprod. Process. , 2016, 98, 283-298.

32 S. A. Heleno, P. P. Diz, M. A. Prieto, L. Barros, A. A. Rodrigues, M. F. Barreiro and I. C. F. R. Ferreira, Optimization of Ultrasound-Assisted Extraction to Obtain Mycosterols from Agaricus Bisporus L. by Response Surface Methodology and Comparison with Conventional Soxhlet Extraction, Food Chem., 2016, 197, 1054-1063.

33 J. Pinela, M. A. Prieto, A. M. Carvalho, M. F. Barreiro, M. B. P. Oliveira, L. Barros and I. C. F. R. Ferreira, Microwave-Assisted Extraction of Phenolic Acids and Flavonoids and Production of Antioxidant Ingredients from Tomato: A Nutraceutical-Oriented Optimization Study, Sep. Purif. Technol., 2016, 164, 114-124.

34 G. Kemmer and S. Keller, Nonlinear Least-Squares Data Fitting in Excel Spreadsheets, Nat. Protocols, 2010, 5, 267-281.

35 S. Prikler, Robert de Levie: Advanced Excel for Scientific Data Analysis, Anal. Bioanal. Chem., 2009, 395, 1945. 
36 C. Comuzzi, P. Polese, A. Melchior, R. Portanova and M. Tolazzi, SOLVERSTAT: A New Utility for Multipurpose Analysis. An Application to the Investigation of Dioxygenated $\mathrm{Co}(\mathrm{II})$ Complex Formation in Dimethylsulfoxide Solution, Talanta, 2003, 59, 67-80.

37 M. Delgado-aguilar, L. Valverde-som and L. Cuadrosrodríguez, Chemometrics and Intelligent Laboratory Systems Solver, an Excel Application to Solve the Difficulty in Applying Different Univariate Linear Regression Methods, Chemom. Intell. Lab. Syst., 2018, 178, 39-46.

38 M. Ranic, M. Nikolic, M. Pavlovic, A. Buntic, S. SilerMarinkovic and S. Dimitrijevic-Brankovic, Optimization of Microwave-Assisted Extraction of Natural Antioxidants from Spent Espresso Coffee Grounds by Response Surface Methodology, J. Clean Prod., 2014, 80, 69-79.

39 J.-H. Xie, C. Dong, S.-P. Nie, F. Li, Z.-J. Wang, M.-Y. Shen and M.-Y. Xie, Extraction, Chemical Composition and Antioxidant Activity of Flavonoids from Cyclocarya Paliurus (Batal.) Iljinskaja Leaves, Food Chem., 2015, 186, 97-105.

40 A. Tomšik, B. Pavlić, J. Vladić, M. Ramić, J. Brindza and S. Vidović, Optimization of Ultrasound-Assisted Extraction of Bioactive Compounds from Wild Garlic (Allium Ursinum L.), Ultrason. Sonochem., 2016, 29, 502-511.

41 F. Chemat, N. Rombaut, A. G. Sicaire, A. Meullemiestre, A. S. Fabiano-Tixier and M. Abert-Vian, Ultrasound Assisted Extraction of Food and Natural Products. Mechanisms, Techniques, Combinations, Protocols and Applications. A Review, Ultrason. Sonochem., 2017, 34, 540-560.

42 Z. Zhu, J. He, G. Liu, F. J. Barba, M. Koubaa, L. Ding, O. Bals, N. Grimi and E. Vorobiev, Recent Insights for the Green Recovery of Inulin from Plant Food Materials Using Non-Conventional Extraction Technologies: A Review, Innovative Food Sci. Emerging Technol., 2016, 33, 1-9.

43 D. Montesano, F. Fallarino, L. Cossignani, A. Bosi, M. S. Simonetti, P. Puccetti and P. Damiani, Innovative Extraction Procedure for Obtaining High Pure Lycopene from Tomato, Eur. Food Res. Technol., 2008, 226, 327-335.

44 M. Carocho, M. F. Barreiro, P. Morales and I. C. F. R. Ferreira, Adding Molecules to Food, Pros and Cons: A Review on Synthetic and Natural Food Additives, Compr. Rev. Food Sci. Food Saf., 2014, 13, 377-399.

45 M. Carocho, P. Morales and I. C. F. R. Ferreira, Natural Food Additives: Quo Vadis?, Trends Food Sci. Technol., 2015, 45, 284-295. 